\title{
INFLUÊNCIA DA ÉPOCA DO ANO NO SUCESSO DA ENXERTIA NAS VARIEDADES DE ABACATEIRO HASS E FORTUNA ${ }^{1}$

\author{
INEZ VILAR DE MORAIS OLIVEIRA², ÍTALOHERBERT LUCENACAVALCANTE ${ }^{3}$, \\ DANILO FRANCO ${ }^{4}$, ANTONIO BALDO GERALDO MARTINS $^{5}$
}

RESUMO - O objetivo do trabalho foi avaliar a influência da época no pegamento da enxertia em abacateiro das variedades Hass e Fortuna, mensalmente, no período de doze meses. As plantas utilizadas pertencem ao Banco de Germoplasma do Departamento de Produção Vegetal da Faculdade de Ciências Agrárias e Veterinárias - UNESP, Câmpus de Jaboticabal-SP. O delineamento experimental utilizado foi o inteiramente casualizado, em esquema fatorial 2 x 12 ('Hass 'e 'Fortuna' e os períodos de enxertia), no intervalo de março de 2005 a fevereiro de 2006, com 10 unidades por parcela, repetidas por quatro vezes. O método utilizado foi a enxertia por garfagem de topo em fenda cheia. As avaliações, 90 dias após a instalação do experimento, foram quanto à porcentagem de pegamento, desenvolvimento total das combinações (porta-enxerto/ enxerto), número de brotações do enxerto, diâmetros acima, abaixo e no local de união do enxerto. O período mais indicado para o sucesso da enxertia está compreendido entre os meses de novembro e dezembro para ambas as variedades de abacateiro.

Termos para indexação: Persea americana Mill, clonagem, propagação.

\section{SEASON INFLUENCE ON GRAFTING SUCCESS OF 'HASS' AND 'FORTUNA'AVOCADO CULTIVARS}

\begin{abstract}
This work aimed to monthly evaluate the influence of seasons of the year on 'Hass' and 'Fortuna' avocado grafting, during twelve months. Plants from the Active Germplasm Bank of Universidade Estadual Paulista, Jaboticabal (SP), Brazil were studied. The experimental design used was completely randomized, in a factorial arrangement 2 x 12 ('Hass` and 'Fortuna' and the months) between March 2005 and February 2006, with 10 unities per plat, repeated four times. The evaluations, 90 days after the beginning of the experiment, were realated to the percentage, total development of the combinations (graft-scion), number of buds, diameters above, below and at the grafting. The most indicated season for grafting is, in general, between November and December for both avocado cultivars.
\end{abstract}

Index terms: Persea americana Mill, cloning, propagation

O abacateiro tem grande expressão econômica no Brasil, sendo considerado o quarto produtor mundial dessa fruta, com uma produção de 175 mil toneladas, atrás apenas do México, Indonésia e Colômbia (Fao, 2006). É cultivado em quase todos os Estados do Brasil, sendo uma das frutíferas mais produtivas por unidade de área cultivada (Tango \& Turatti, 1992). Atualmente, o Estado de São Paulo destaca-se como o maior produtor brasileiro, com 4.560 ha e uma produção de 91.981 toneladas (Ibraf, 2006).

A propagação vegetativa é uma técnica que consiste em reproduzir indivíduos sem modificações em sua constituição genotípica, a partir de partes vegetativas bem diferenciadas, o que não acontece na propagação sexuada devido à segregação ou combinação gênica. Nesse sentido, a propagação vegetativa tem a vantagem, se não ocorrerem mutações, da obtenção de plantas uniformes em constituição genética, além de produzirem mais cedo do que as propagadas por semente (Hartmann et al., 2002). Tradicionalmente, o abacateiro é propagado por enxertia de uma cultivar-copa de interesse econômico, sobre portaenxertos oriundos de sementes (Koller, 2002).

A enxertia é vista como a arte de união de partes de diferentes da planta, de maneira que passem e constituir uma unidade e dando continuidade ao crescimento. Thouin (1821), citado por Bailey (1944), descreveu 119 diferentes maneiras de se proceder à enxertia e assinala que, para o sucesso do procedimento, há necessidade de se justapor o tecido cambial de ambas as partes envolvidas e de proteger apropriadamente a região.

A base da enxertia é a união dos biontes (hipobionte e epibionte, conhecido por porta-enxerto e enxerto, respectivamente), que ocorre através do contato e pelo entrelaçamento dos calos produzidos pelo câmbio, como

1'(Trabalho 152-07). Recebido em: 19-06-2007. Aceito para publicação em: 29-10-2007.

${ }^{2}$ Doutora em Produção Vegetal - Bolsista DCR - Embrapa Semi-Árido, Petrolina-PE - e-mail: inezvilar@yahoo.com

${ }^{3}$ Prof. Universidade Federal do Piauí, Campus Profa. Cinobelina Elvas, Bom Jesus-PI. Doutorando FCAV/UNESP.

e-mail: italohlc@ufpi.edu.br

${ }^{4}$ Pós-Graduando em Agronomia - Produção Vegetal - UNESP/FCAV, Jaboticabal-SP. Bolsista CAPES

e- mail:franco.danilo@gmail.com

${ }^{5}$ Prof. Doutor - Depto de Produção Vegetal - UNESP/FCAV, Jaboticabal-SP . e-mail: baldo@fcav.unesp.br 
resultado da reação ao corte dos tecidos. Esse calo, sob a influência do câmbio existente, diferencia um novo tecido cambial que, por sua vez, dá origem ao xilema, na parte interna, e floema, na externa, repondo a conexão vascular entre os dois biontes (Janick, 1966; Jeffree \& Yeoman, 1983).

A época de realização de enxertia encontra-se entre os fatores externos que podem afetar o pegamento. Normalmente, espécies tropicais apresentam ótimos índices de pegamento quando os enxertos são realizados sob temperaturas em torno de $30^{\circ} \mathrm{C}$, quando se tem maior atividade cambial (Hartmann et al., 2002).

O objetivo deste trabalho foi identificar a época do ano na qual ocorre o melhor pegamento do enxerto de abacate, em duas variedades: Hass e Fortuna, durante o período de doze meses.

O experimento foi conduzido na Faculdade de Ciências Agrárias e Veterinárias (FCAV), da Universidade Estadual Paulista (UNESP), Câmpus de Jaboticabal, com plantas do Banco Ativo de Germoplasma de Fruticultura do Departamento de Produção Vegetal.

Para a obtenção do material a ser utilizado como portaenxerto, foram coletadas sementes de abacateiro Fortuna, colocadas para germinar em sacos de polietileno preto com 15 $\mathrm{cm}$ de diâmetro e $30 \mathrm{~cm}$ de altura, preenchidos com substrato formado pela mistura de solo + areia + esterco de curral curtido (3:3:1), sob condições de ripado, $50 \%$ de luminosidade e irrigação diária pelo sistema de microaspersão.

Os garfos foram retirados de ramos coletados na região mediana das copas das plantas. Imediatamente após, retiraramse as folhas, e os garfos foram acondicionados em sacos plásticos, para evitar a desidratação. Para cada variedade Hass e Fortuna, utilizaram-se cinco plantas adultas.

A enxertia foi realizada quando as mudas apresentavam diâmetro do caule em torno de 1,0 a $15 \mathrm{~cm}$ do colo e altura de 35 $\mathrm{cm}$, utilizando o método de enxertia por garfagem de topo em fenda cheia. Foram utilizados garfos de ramos ponteiros semiherbáceos, com 5 a 6 gemas. Foi feito um corte horizontal no porta-enxerto a uma altura de $15 \mathrm{~cm}$ do nível do substrato e, posteriormente, com um canivete de enxertia, efetuou-se corte longitudinal, abrindo-se uma fenda, onde foi introduzido o garfo, com corte em cunha na base, que foi fixado com parafilme. A enxertia foi realizada somente por um enxertador, para reduzir variação nos resultados.

Para a proteção contra ressecamento do enxerto, foram utilizados sacos de polietileno com dimensões de 4 x $23 \mathrm{~cm}$. Esse saco foi colocado, cobrindo o enxerto, e amarrado com fitilho ao porta-enxerto abaixo do ponto de enxertia. O saco de polietileno foi retirado após o início da brotação.

O delineamento experimental utilizado foi o inteiramente casualizado, em esquema fatorial 2 x 12 ('Hass'e 'Fortuna' e 12 meses de realização das enxertia), no intervalo de março de 2005 a fevereiro de 2006. Cada parcela foi composta por 10 mudas, com 4 repetições cada.

Após 90 dias da realização da enxertia, avaliaram-se a porcentagem de pegamento, o desenvolvimento total das combinações (porta-enxerto/enxerto), o número de brotações do enxerto e os diâmetros acima, abaixo e no local de união do enxerto. No final do experimento, observou-se através de fotografias o tecido na região da enxertia do porta-enxerto e do enxerto.

Foi realizada análise de variância e as médias foram comparadas pelo teste de Tukey, a 1\%, utilizando-se do software Assistat (Silva, 1996).

Praticamente não houve diferença entre as variedades Hass e Fortuna quanto à distribuição da porcentagem de pegamento em função dos meses do ano (Figura 1), observandose valores máximos de 42,5 e $70 \%$, respectivamente, para as variedades Hass e Fortuna, no mês de novembro. É possível observar uma diminuição de pegamento nas duas variedades, nos meses de agosto-setembro e janeiro-fevereiro, períodos em que os tecidos estavam diferenciando-se; isso pode ser explicado devido à presença de medula branca nos enxertos, que é um tecido "esponjoso" branco, dificultando a soldadura dos tecidos do enxerto com os do porta-enxerto. Adicionalmente, a interação entre os fatores estudados em relação à porcentagem de pegamento dos enxertos não foi significativa.

Analisando-se o percentual de pegamento total dos experimentos, observa-se que a variedade Fortuna $(38,54 \%)$ foi estatisticamente superior à variedade Hass $(21,04 \%)$ com superioridade quantitativa de aproximadamente $17 \%$.

Fisiologicamente, as fases de crescimento das plantas que coincidem com uma baixa atividade do tecido cambial, geralmente indicam uma fase de baixa probabilidade de sucesso da propagação por enxertia. A retirada de garfos para a enxertia durante as fases de crescimento reprodutivo (floração e frutificação) também se apresenta como fase não-recomendada, pois, nessa época, a planta destina suas reservas para a formação dos órgãos de reprodução, ficando o tecido cambial com baixa disponibilidade de carboidratos para a cicatrização do ferimento ocasionado pela operação. Além dos aspectos relacionados com a atividade celular, existe ainda a situação hormonal da planta, modificada durante as diferentes fases fenológicas, podendo favorecer ou não a cicatrização da enxertia (Hartmann et al., 2002). Em Jaboticabal-SP, observou-se que a floração ocorreu no mês de agosto para as duas variedades de abacate estudadas (Hass e Fortuna) (Oliveira s.d., dados não-publicados) período em que foi possível observar os piores resultados de pegamento dos enxertos.

Estudos referentes às melhores épocas e métodos de enxertia têm sido realizados com outras espécies, como o conduzido por Gonzaga Neto (1982), que recomenda os meses de agosto e setembro como os mais propícios para a enxertia em goiabeira (Psidium guajava L.), muito embora Gama et al. (1989) tenham identificado o mês de maio como a melhor época para a enxertia da mesma cultura. Islam et al. (2004) determinaram que, em Bangladesh, o melhor período para realizar a enxertia da manga é em junho, apresentando maiores valores de crescimento e de pegamento, mostrando, como no presente estudo, que a época do ano tem diferença direta no sucesso da enxertia para diferentes espécies. Por outro lado, na Turquia, Özkan \& Gümü S (2001) observaram, para nogueira, que não há diferença para o pegamento das enxertias realizadas nos meses de janeiro, fevereiro e março. 
A variedade Fortuna pertence à raça antilhana, e o Hass é um híbrido entre as raças guatemalense e mexicana. Possivelmente, devido às sementes obtidas para a formação dos porta-enxertos terem sido obtidas de plantas pertencentes à raça antilhana, ocorreu melhor índice de pegamento na variedade 'Fortuna', explicando-se a partir da afinidade botânica existente.

Para as variáveis apresentadas na Tabela 1 (diâmetros acima, abaixo e no local de união do enxerto), sempre os maiores resultados foram obtidos entre os meses de outubro e dezembro, independentemente da variedade estudada. Comparando-se as duas variedades, pode-se observar que não há tendência de superioridade homogênea definida entre elas nos meses do ano. Como pode ser observado na Figura 1, parece não haver relação direta da temperatura ambiente no pegamento da enxertia, em abacateiro das variedades Hass e Fortuna.

De forma semelhante aos diâmetros apresentados na Tabela 1, observa-se para os resultados da altura de plantas na Tabela 2, destacando-se a discrepante diferença entre as variedades, ocorrida nos meses de agosto e fevereiro, quando a
'Hass' foi bastante inferior à 'Fortuna'. Acompanhando essa tendência, está o número de brotos que, independentemente do mês de enxertia, foi superior para a 'Fortuna' (Tabela 2).

Nas Figuras 2A e 3A, observa-se na região da enxertia o tecido do porta-enxerto e do enxerto com necrose interna, um mês após a enxertia. Nas Figuras $2 \mathrm{~B}$ e 3B, no detalhe da região enxertada, após 12 meses, é possível verificar que a região necrosada já havia diminuído, sendo preenchida pelo novo tecido que se formava, proporcionando uma eficiente soldadura; isso foi possível observar nas duas variedades estudadas, embora o processo seja mais rápido para a 'Fortuna'.

A época do ano afeta o resultado da enxertia.

O período mais indicado para realização de enxertia está compreendido entre os meses de novembro e dezembro.

Por cerca de doze meses após a enxertia, a união do enxerto com o porta-enxerto ainda não está completa, principalmente para a variedade Hass.
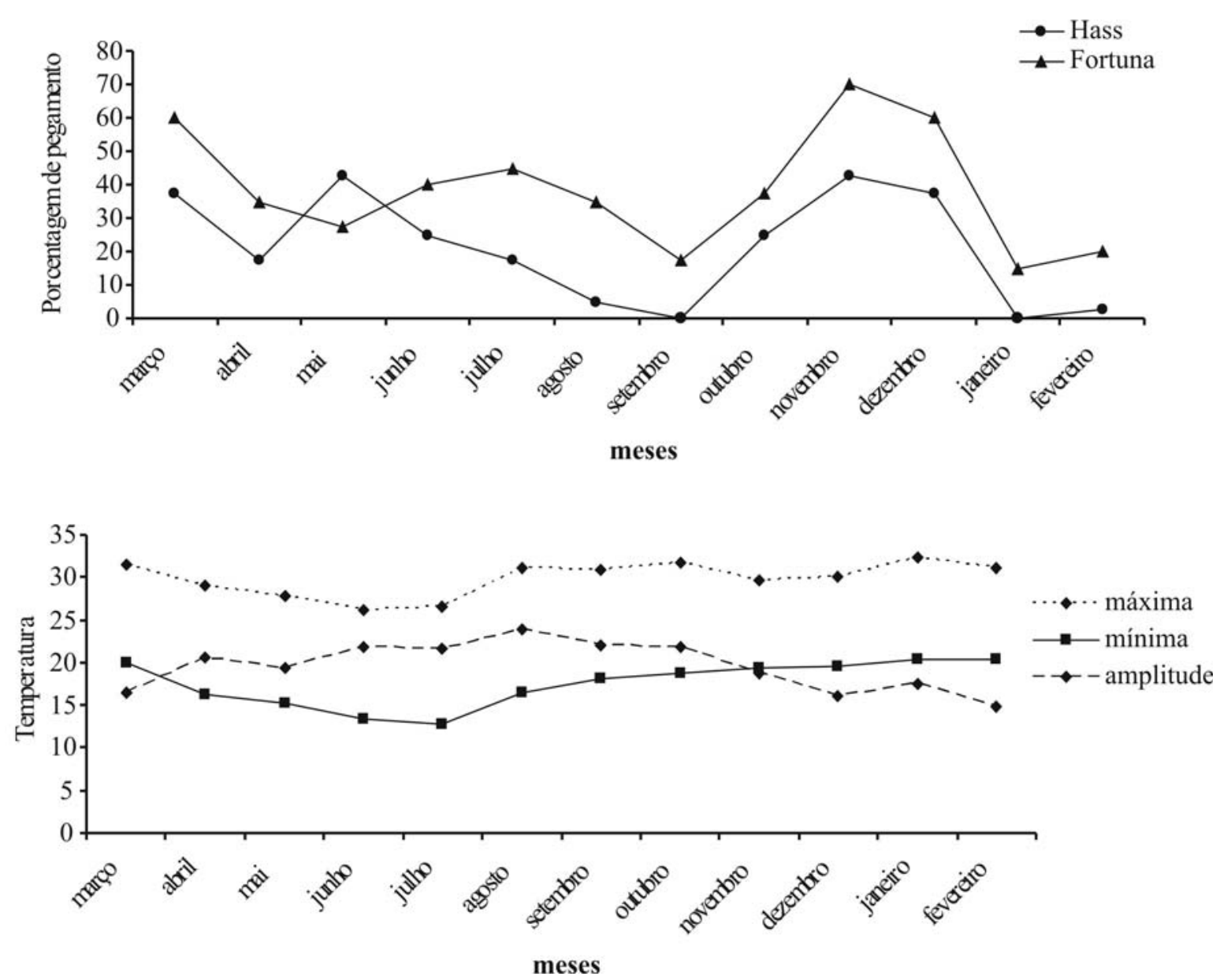

FIGURA 1 - Porcentagem de enxertia em determinados meses do ano (A) e temperaturas mínima, máxima e amplitude térmica, no período de março de 2005 a fevereiro de 2006. 
TABELA 1- Diâmetro do caule abaixo, na região da enxertia e acima de duas variedades de abacate: 'Hass' e 'Fortuna'.

\begin{tabular}{|c|c|c|c|c|c|c|}
\hline \multirow[b]{2}{*}{ Meses } & \multicolumn{2}{|c|}{ inferior $(\mathrm{cm})$} & \multicolumn{2}{|c|}{ enxerto $(\mathrm{cm})$} & \multicolumn{2}{|c|}{ superior $(\mathrm{cm})$} \\
\hline & Hass & Fortuna & Hass & Fortuna & Hass & Fortuna \\
\hline março & $6,96 \mathrm{aA}$ & $6,31 \mathrm{aAB}$ & $7,94 \mathrm{aA}$ & $7,48 \mathrm{aAB}$ & $5,95 \mathrm{aABC}$ & $6,06 \mathrm{aA}$ \\
\hline abril & $5,25 \mathrm{aAB}$ & $5,50 \mathrm{aAB}$ & $6,94 \mathrm{aA}$ & $6,50 \mathrm{aAB}$ & 5,59aABC & $5,66 \mathrm{aA}$ \\
\hline maio & $5,57 \mathrm{aAB}$ & $5,53 \mathrm{aAB}$ & $7,55 \mathrm{aA}$ & $7,56 \mathrm{aAB}$ & $6,36 \mathrm{aA}$ & $6,01 \mathrm{aA}$ \\
\hline junho & $5,20 \mathrm{aAB}$ & $5,53 \mathrm{aAB}$ & $6,85 \mathrm{aA}$ & $7,23 \mathrm{aAB}$ & $6,04 \mathrm{aABC}$ & $5,44 \mathrm{aA}$ \\
\hline julho & $5,28 \mathrm{aAB}$ & $5,53 \mathrm{aAB}$ & $7,16 \mathrm{aA}$ & $7,49 \mathrm{aAB}$ & $6,30 \mathrm{aA}$ & $6,29 \mathrm{aA}$ \\
\hline agosto & $2,54 \mathrm{bBC}$ & $5,30 \mathrm{aAB}$ & $3,05 \mathrm{bB}$ & $7,00 \mathrm{aAB}$ & $2,72 \mathrm{bBCD}$ & $5,54 \mathrm{aA}$ \\
\hline setembro ${ }^{*}$ & $0,00 \mathrm{bC}$ & $3,40 \mathrm{aB}$ & $0,00 \mathrm{bB}$ & $5,26 \mathrm{aB}$ & $0,00 \mathrm{bD}$ & $4,13 \mathrm{aA}$ \\
\hline outubro & $7,49 \mathrm{aA}$ & $7,82 \mathrm{aA}$ & $8,05 \mathrm{aA}$ & $8,74 \mathrm{aAB}$ & $6,57 \mathrm{aA}$ & $7,43 \mathrm{aA}$ \\
\hline novembro & $7,76 \mathrm{aA}$ & $7,64 \mathrm{aA}$ & $9,55 \mathrm{aA}$ & $9,40 \mathrm{aA}$ & $7,04 \mathrm{aA}$ & $6,66 \mathrm{aA}$ \\
\hline dezembro & $8,04 \mathrm{aA}$ & $7,71 \mathrm{aA}$ & $9,21 \mathrm{aA}$ & $9,69 \mathrm{aA}$ & $6,11 \mathrm{aA}$ & $6,36 \mathrm{aA}$ \\
\hline janeiro ${ }^{*}$ & $0,00 \mathrm{bC}$ & $6,27 \mathrm{aAB}$ & $0,00 \mathrm{bB}$ & $8,99 \mathrm{aAB}$ & $0,00 \mathrm{bD}$ & $7,21 \mathrm{aA}$ \\
\hline fevereiro & $2,12 \mathrm{bC}$ & $7,15 \mathrm{aA}$ & $2,38 \mathrm{bB}$ & $8,22 \mathrm{aAB}$ & $2,56 \mathrm{bCD}$ & $6,13 \mathrm{aA}$ \\
\hline $\mathrm{CV} \%$ & \multicolumn{2}{|c|}{23,66} & \multicolumn{2}{|c|}{23,13} & \multicolumn{2}{|c|}{27,67} \\
\hline DMS coluna & \multicolumn{2}{|c|}{1,82} & \multicolumn{2}{|c|}{2,22} & \multicolumn{2}{|c|}{2,08} \\
\hline DMS linha & \multicolumn{2}{|c|}{3,08} & \multicolumn{2}{|c|}{3,75} & \multicolumn{2}{|c|}{3,53} \\
\hline
\end{tabular}

Médias seguidas de mesma(s) letra(s) maiúscula(s) nas colunas e minúsculas na(s) linha(s) não diferem entre si, pelo teste de Tukey (p $\leq 0,01$ ). *Não houve pegamento para a variedade Hass.

TABELA 2- Altura e número de brotos de duas variedades de abacate: 'Hass' e 'Fortuna'.

\begin{tabular}{|c|c|c|c|c|}
\hline \multirow[t]{2}{*}{ Meses } & \multicolumn{2}{|c|}{ Altura $(\mathrm{cm})$} & \multicolumn{2}{|c|}{ Número de Broto } \\
\hline & Hass & Fortuna & Hass & Fortuna \\
\hline março & $38,75 \mathrm{aAB}$ & $37,75 \mathrm{aA}$ & $2,35 \mathrm{bABC}$ & $4,51 \mathrm{aAB}$ \\
\hline abril & $35,42 \mathrm{aAB}$ & $40,50 \mathrm{aA}$ & $1,82 \mathrm{aABC}$ & $2,25 \mathrm{aB}$ \\
\hline maio & $38,66 \mathrm{aAB}$ & $37,95 \mathrm{aA}$ & $2,09 \mathrm{aABC}$ & $3,31 \mathrm{aAB}$ \\
\hline junho & $39,48 \mathrm{aAB}$ & $33,32 \mathrm{aA}$ & $2,35 \mathrm{aABC}$ & $2,79 \mathrm{aAB}$ \\
\hline julho & $35,91 \mathrm{aAB}$ & $34,50 \mathrm{aA}$ & $2,50 \mathrm{aABC}$ & $3,13 \mathrm{aAB}$ \\
\hline agosto & $19,50 \mathrm{aBC}$ & $27,62 \mathrm{aA}$ & $1,50 \mathrm{aABC}$ & $2,41 \mathrm{aB}$ \\
\hline setembro & $0,00 \mathrm{bC}$ & $22,83 \mathrm{aA}$ & $0,00 \mathrm{bC}$ & $2,00 \mathrm{aB}$ \\
\hline outubro & $32,37 \mathrm{aAB}$ & $39,26 \mathrm{aA}$ & $3,57 \mathrm{aA}$ & $3,93 \mathrm{aAB}$ \\
\hline novembro & $47,78 \mathrm{aA}$ & $38,00 \mathrm{aA}$ & $3,72 \mathrm{aA}$ & $3,90 \mathrm{aAB}$ \\
\hline dezembro & $38,87 \mathrm{aAB}$ & $37,11 \mathrm{aA}$ & $2,88 \mathrm{aAB}$ & $3,94 \mathrm{aAB}$ \\
\hline janeiro & $0,00 \mathrm{bC}$ & $35,37 \mathrm{aA}$ & $0,00 \mathrm{bC}$ & $5,00 \mathrm{aA}$ \\
\hline fevereiro & $11,75 \mathrm{bC}$ & $37,96 \mathrm{aA}$ & $0,75 \mathrm{bBC}$ & $3,68 \mathrm{aAB}$ \\
\hline $\mathrm{CV} \%$ & \multicolumn{2}{|c|}{26,99} & \multicolumn{2}{|c|}{39,29} \\
\hline DMS coluna & \multicolumn{2}{|c|}{12,06} & \multicolumn{2}{|c|}{1,48} \\
\hline DMS linha & \multicolumn{2}{|c|}{20,43} & \multicolumn{2}{|c|}{2,52} \\
\hline
\end{tabular}

Médias seguidas de mesma(s) letra(s) maiúscula(s) nas colunas e minúsculas na(s) linha(s) não diferem entre si, pelo teste de Tukey (p $\leq 0,01$ ). 


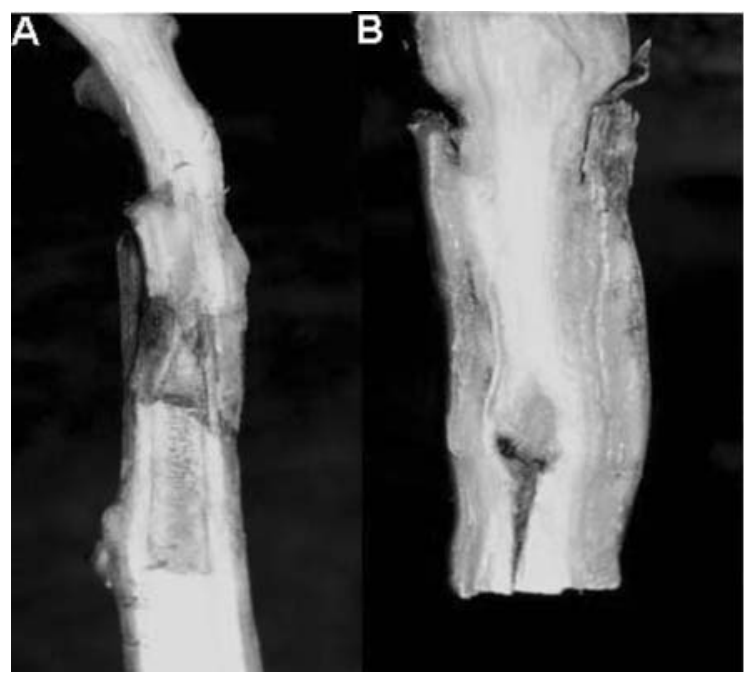

FIGURA 2- Enxerto da variedade Fortuna em porta-enxerto obtido de semente. A- região da enxertia, um mês após a enxertia. B- região da enxertia, 12 meses após a enxertia. Jaboticabal-SP, 2006

\section{REFERÊNCIAS}

BAILEY, L. H. The standart encyclopedia of horticulture. New York: The Macmillan 1944. p.1362-1371.

FAO. FOOD AGRICULTURAL ORGANIZATION. Statistics database. Disponível em: <www.apps.fao.org>. Acesso em: 14 abr. 2006.

GAMA, F. S. N. da; KIST, H. G.; ACCORST, M. R. Efeito da época de enxertia e do tipo de garfo sobre o pegamento de enxertos de goiabeira (Psidium guajava L.). Revista Brasileira de Fruticultura, Jaboticabal, v.11, n. 2, p .45-47, 1989.

GONZAGA NETO, L. Estudos de métodos de produção de portaenxerto e de enxertia da goiabeira (Psidium guajava $L$.). 1982. 51 f. Dissertação (Mestrado) - Unversidade Federal de Viçosa, Viçosa, 1982.

HARTMANN, H. T.; KESTER, D. E.; DAVIES JR., F. T.; GENEVE, R. L. Plant propagation: principles and practices. New Jersey: PRENTICE-HALL, 2002. $880 \mathrm{p}$.

IBRAF. INSTITUTO BRASILEIRO DE FRUTICULTURA. Disponível em: <www.ibraf.org.br>. Acesso em : 14 set. 2006.

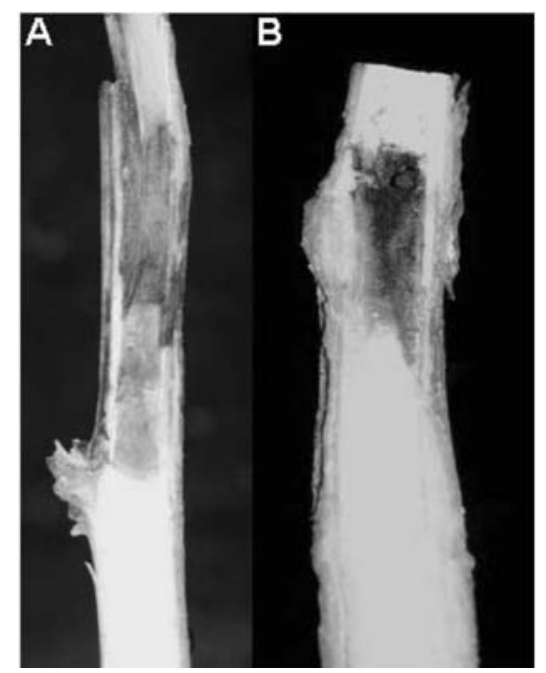

FIGURA 3- Enxerto da variedade Hass em porta-enxerto obtido de semente. A- região da enxertia, um mês após a enxertia. B- região da enxertia, 12 meses após a enxertia. Jaboticabal-SP, 2006.

ISLAM, M. N.; RAHIM, M. A.; FAROOQUE, A. M. Standardization of Time and Grafting Techniques in Mango under Bangladesh Condition. Asian Journal of Plant Sciences, Secunderabad, v.3, n.3, p.378-386, 2004.

JANICK, J. A ciência da horticultura. Rio de Janeiro: Freitas Bastos, 1966. p. 485.

JEFFREE, C. E.;. YEOMAN, M. M. Development of intercellular connections between opposing cells in graft unions. New Phytologist, New York, v.93, n.4, p. 491-509, 1983.

KOLLER, O. Abacate: produção de mudas, instalação, manejo de pomares, colheita e pós-colheita. Porto Alegre: Cinco Continentes, 2002.154p.

ÖZKAN, Y.; GÜMÜ S, A. Effects of different applications on grafting under controlled conditions of walnut (Juglans regia 1.). Acta Horticulturae, Wageningen, n. 544, p. 515-520, 2001.

SILVA, F. de A.S. The assistat Software: statistical assistance. In: INTERNATIONAL CONFERENCE ON COMPUTERS IN AGRICULTURE, 6., 1996. Cancun. Anais... Cancun: American Society of Agricultural Engineers, 1996. p. 294-298.

TANGO, J. S.; TURATTI, J. M. Óleo de abacate. In: ITAL. Abacate: cultura, matéria-Prima, processamento e aspectos econômicos. Campinas: ITAL, 1992. p. 156-192. 